Article

\title{
Opening up ZSM-5 Hierarchical Zeolite's Porosity through Sequential Treatments for Improved Low-Density Polyethylene Cracking ${ }^{\dagger}$
}

\author{
Karolina A. Tarach * ${ }^{\mathbb{B}}$, Kamila Pyra $₫$ and Kinga Góra-Marek \\ Faculty of Chemistry, Jagiellonian University in Kraków, 2 Gronostajowa St., 30-87 Kraków, Poland; \\ kamila.pyra@doctoral.uj.edu.pl (K.P.); kinga.gora-marek@uj.edu.pl (K.G.-M.) \\ * Correspondence: karolina.tarach@uj.edu.pl \\ † Dedicated to Professor Jerzy Datka in appreciation of his outstanding contribution to zeolite science.
}

Academic Editors: Jerzy Datka, Włodzimierz Mozgawa and Dorota Rutkowska-Zbik Received: 7 May 2020; Accepted: 18 June 2020; Published: 22 June 2020

\begin{abstract}
An adequately tuned acid wash of hierarchical ZSM-5 zeolites offers a levelling up in the catalytic cracking of low-density polyethylene. Identification of crucial and limiting factors governing the activity of the zeolite was extended with studies about the accessibility of acid sites, nature of the realuminated layer and role of Lewis acid sites. The sequential treatment of a ZSM- 5 zeolite offered enhanced activity in low-density polyethylene (LDPE) cracking at low and high conversions, as confirmed by a decrease in the temperatures needed to reach $20 \%$ and $80 \%$ conversion $\left(\mathrm{T}_{20}\right.$ and $\mathrm{T}_{80}$, respectively). A linear dependence of the $\mathrm{T}_{80}$ on the coupled IHF (indexed hierarchy factor) and $\mathrm{AF}_{\mathrm{B}}$ (accessibility factor) highlighted the importance of the textural and acidic parameters in the catalytic cracking of LDPE. Operando FT-IR-GC studies confirmed a higher fraction of short-chain hydrocarbons $\left(\mathrm{C}_{3}-\mathrm{C}_{5}\right)$ in the product distribution of hierarchical catalysts resulting from the effective polymer cracking in easily accessible pores.
\end{abstract}

Keywords: hierarchical zeolites; acid-wash; Lewis acid sites; operando spectroscopy; LDPE cracking; realumination

\section{Introduction}

Hierarchical zeolites are known to efficiently crack polymers or vacuum gas oil, giving high selectivity to most desirable products [1-5]. The benefits to these cracking reactions are the combination of a secondary mesopore system coupled with the intrinsic acidity of microporous zeolites $[6,7]$. The ZSM- 5 zeolites are known to produce light olefins in the selective cracking of $\mathrm{C}_{6}-\mathrm{C}_{9}$ molecules; thus, they are expected to be an integral contributor to meeting the continuing global demand for light olefins [8]. The susceptibility of ZSM-5 zeolites to bottom-up modification has fuelled studies concerning the application of hierarchical ZSM-5 zeolites in cracking reactions [4,9]. Demetallation processes, i.e., desilication and dealumination, are highly versatile methods of hierarchical zeolite preparation; appropriately defined modification conditions ensure that hierarchical porosity can be obtained independently of $\mathrm{Si} / \mathrm{Al}$ ratio, structure type or grains size [10,11]. Substantial interference in zeolite structure due to $\mathrm{Si}$ and $\mathrm{Al}$ atom extraction, however, leads to a significant alteration of the acid sites' nature, preferentially with the formation of Lewis acid sites in a large number [12,13]. These Lewis acid sites are found in the majority on the newly created mesopores' surface, as they originate from the Al-enriched layer formed during realumination process [13,14]. Although the acid sites' accessibility increases upon desilication, the full potential of such hierarchical zeolites can be reached only by further precise treatment. 
The improvement of the catalytic performance of zeolites containing EFAl (extra-framework Al) species originating from steaming or acid treatment in the cracking of alkanes remains a long-standing debate in zeolite science [8]. Many approaches have been considered, among them the possibility of EFAl being an active site for hydrocarbon activation, inductive influence of EFAl on Brønsted sites or enhancing acidity of Brønsted sites by withdrawing the electron density of neighbouring $\mathrm{Si}(\mathrm{OH}) \mathrm{Al}$ groups [8]. Nevertheless, it has also been shown that the removal of the Al-rich debris originating from desilication by subsequent acid treatment increases the activity of desilicated ZSM- 5 zeolites for the alkylation of toluene with benzyl alcohol [10]. Additionally, extra-framework Al species formed via hydrolysis of framework Al perturbed or dislodged by desilication have been shown to restrict part of the channel structure of mordenite zeolite [15]. Their subsequent removal by mild acid leaching resulted in unrestricted channel openings and led to a large increase in the accessibility of $\mathrm{Si}(\mathrm{OH}) \mathrm{Al}$ groups for $n$-hexane. In contrast, the presence of unique Lewis acid sites formed by desilication enhances the isomerisation of dihydroxyacetone (DHA) to lactic acid (LA) [16]. The origin of these unique Lewis acid sites is still under debate. Generally, their formation is ascribed to the high susceptibility to dehydroxylation of the non-framework protonic sites of the realuminated layer $[13,17]$. The influence of the Lewis acid sites, and also of sequential treatments, on the catalytic activity have not been yet studied in polymer-cracking reactions.

Our previous study showed that a hierarchical ZSM-5 zeolite obtained by post-synthesis desilication was an effective catalyst for the cracking of low-density and high-density polyethylene (PE) polymers [4]. A linear correlation between the temperature necessary for reaching 50\% PE conversion $\left(T_{50}\right)$ and acid sites accessibility indicated, with certainty, that an enhancement of mesopore surface area by hierarchisation led to an improvement in the $T_{50}$ values. Nevertheless, for the hierarchical zeolite with the highest external surface area, the cracking activity was not improved as much as was expected by optimising the desilication conditions. That led us to the conclusion that the realuminated layer at the outer part of the zeolite grains may have been responsible for hindering the full potential of these zeolites in the PE-cracking reactions.

This work was devoted to proving the hypothesis of the negative influence of the realuminated layer on the polymer cracking. Sequential alkaline (deSi; desilication) and acidic (Ac; dealumination) treatments on a microporous ZSM-5 zeolite were performed, and the catalytic performance was verified in low-density polyethylene (LDPE) cracking. The comprehensive structural, textural and acidic characteristics of hierarchical zeolites were linked to their catalytic activity and selectivity.

\section{Results and Discussion}

The catalytic LDPE cracking results showed that the zeolites modified in a sequential manner (deSi-ZSM-5\&Ac $\left.{ }^{*}\right)$ ) were significantly more active in comparison to the desilicated cases (deSi-ZSM-5) (Figure 1). The $T_{50}$ value was lowered from $325^{\circ} \mathrm{C}$ to $300^{\circ} \mathrm{C}$ for mild-acid-washed deSi-ZSM-5\&Ac(m) compared with deSi-ZSM-5. Similarly, at the lower temperatures range, the $T_{20}$ value shifted from 295 to $250^{\circ} \mathrm{C}$, giving the most pronounced enhancement of the cracking activity. However, only the carefully chosen conditions for the zeolite acid wash, deSi-ZSM- $\& \& A c(m)$, allowed this optimal activity to be achieved. Compared to the mild washing, when a more severe dealumination was applied, a decline of the activity was seen, as for the deSi-ZSM-5\&Ac(s) sample. In general, the catalytic activity benefitted more from dealumination at reaction temperatures below $300^{\circ} \mathrm{C}$, and at higher temperatures, the acid-washed materials, particularly deSi-ZSM-5\&Ac(s), resembled those that were desilicated only ( $T_{80}$ values differ slightly). 


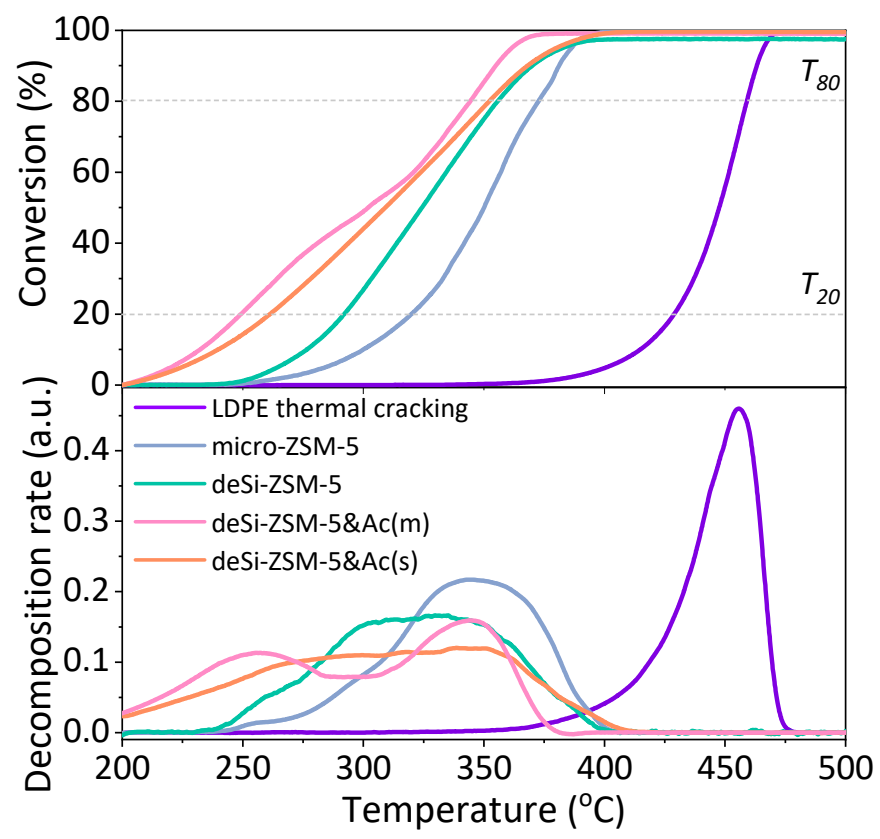

Figure 1. (Upper) LDPE (low-density polyethylene) catalytic cracking conversion curves $\left(T_{20}\right.$ and $T_{80}$ the temperatures necessary for reaching $20 \%$ and $80 \%$ conversion) and (lower) decomposition rates of the studied zeolites as a function of temperature.

The enhancement in the catalytic activity of the modified zeolites, both desilicated and sequentially treated, can be explained by the upgraded textural and acidic properties. The increase of the mesoporous surface area upon desilication and related changes in the acidic properties enabled a higher catalytic activity. Furthermore, subsequent acid washing altered neither the structure nor the porosity (Table 1). The desilication itself led to the development of mesopore surface area $\left(S_{\text {meso }}=146 \mathrm{~m}^{2} \mathrm{~g}^{-1}\right)$, accompanied only by a slight drop of the crystallinity (Cryst. $=84 \%$, Supplementary Figure S1). The sequentially treated zeolites displayed crystallinity and porous characteristic parameters $\left(S_{B E T}, V_{\text {micro }}\right)$ similar to those of the deSi-ZSM-5. The acid washing did not affect the course of low-temperature $\mathrm{N}_{2}$ sorption isotherm, maintaining the mixed Type I/IV shape. The pore size distribution, with a broad range of mesopore sizes, was also preserved (Supplementary Figure S2). A fair indication of changes in the textural parameters was obtained via the indexed hierarchy factor (IHF, see Table 1) [10]. Higher IHF values point to a greater share of mesopores with preserved microporosity, while lower IHF values represent materials with excessive microporosity or mesoporosity. A comparable hierarchisation degree was quantitatively confirmed by the IHF values, ranging from 0.66 to 0.71 . Visual proof of the formation of mesopores after desilication, and their preservation upon dealumination, was seen on STEM and TEM micrographs (Figure 2 and Supplementary Figure S3). All these textural findings indicated that the superior catalytic activity of the sequentially treated ZSM-5 zeolites should be related to their acidic features, being a derivative of $\mathrm{Al}$ content and speciation, since the crystallinity and texture did not change significantly with respect to the deSi-ZSM-5. Noticeable changes upon dealumination, compared with desilication were, however, seen in the chemical composition (ICP, Table 1) and Al distribution (EDX, FT-IR; Figure 2, Supplementary Figures S4 and S5) of the final materials. The expected drop of $\mathrm{Si} / \mathrm{Al}$ after desilication (from 32 to 18 ) was followed by its increase for the sequentially treated deSi-ZSM-5-Ac(*) zeolites (from 18 to $22(\mathrm{~m})$ or $25(\mathrm{~s})$ ). The leaching of $\mathrm{Al}$ from the zeolite surface grains in the dealumination process was also proved by EDX analysis. The $\mathrm{Al}$ atom distribution over the external surface of the zeolite grains upon dealumination (desi-ZSM-5\&Ac $(\mathrm{m})$ ) was significantly altered (Figure 2). 


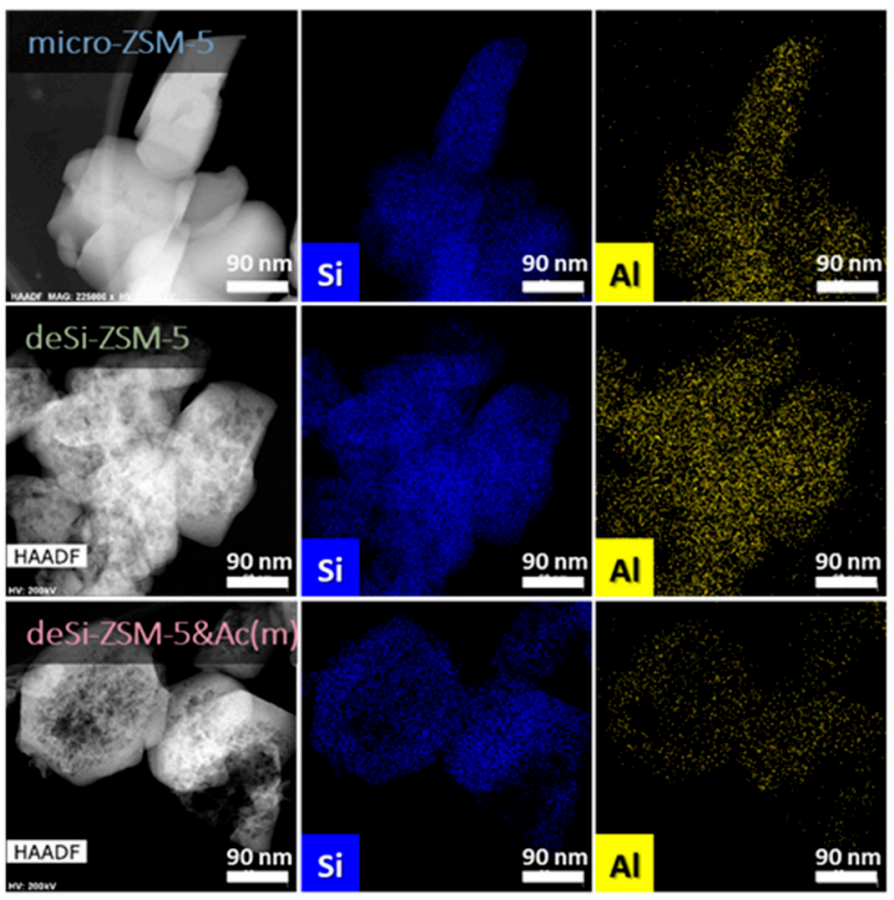

Figure 2. STEM images and EDX maps of Si and Al distribution in studied zeolites.

Table 1. Chemical composition, crystallinity and textural parameters of studied zeolites.

\begin{tabular}{|c|c|c|c|c|c|c|}
\hline & $\mathrm{Si} / \mathrm{Al}^{\mathrm{a}}$ & Cryst. ${ }^{b} \%$ & $S_{B E T}{ }^{\mathrm{c}} \mathrm{m}^{2} \mathrm{~g}^{-1}$ & $S_{\text {meso }}{ }^{\mathrm{d}} \mathrm{m}^{2} \mathrm{~g}^{-1}$ & $V_{\text {micro }} \mathrm{e}^{\mathrm{cm}} \mathrm{cm}^{3} \mathrm{~g}^{-1}$ & IHF $^{f}$ \\
\hline micro-ZSM-5 & 32 & 100 & 377 & 40 & 0.17 & 0.21 \\
\hline deSi-ZSM-5 & 18 & 84 & 517 & 146 & 0.16 & 0.71 \\
\hline deSi-ZSM-5\&Ac(m) & 22 & 83 & 501 & 144 & 0.15 & 0.66 \\
\hline deSi-ZSM-5\&Ac(s) & 25 & 78 & 499 & 148 & 0.15 & 0.68 \\
\hline
\end{tabular}

${ }^{a}$ Concentrations of $\mathrm{Si}$ and $\mathrm{Al}$ from chemical analysis (ICP), expressed as $\mathrm{Si} / \mathrm{Al}$ ratio. ${ }^{\mathrm{b}}$ Calculated based on XRD patterns in the range of $22.5^{\circ}$ to $25.0^{\circ}$. ${ }^{\mathrm{C}}$ Calculated via BET method with the recommendations of Rouquerol et al. [18]

${ }^{\mathrm{d}}$ Calculated as the difference between $S_{B E T}$ and $S_{\text {micro }} .{ }^{\mathrm{e}}$ Calculated via the $t$-plot method. ${ }^{\mathrm{f}}$ IHF (indexed hierarchy factor) calculated as $\left(V_{\text {micro }} / V_{\text {micro,max }}\right) \times\left(S_{\text {meso }} / S_{\text {meso,max }}\right)$ [10]; $V_{\text {micro, } \text { max }}$ and $S_{\text {meso, max }}$ based on Reference [4].

The changes of chemical composition and $\mathrm{Al}$ distribution over the zeolite grains were reflected in the acidic properties (Table 2 and Supplementary Table S1).

Table 2. Acid sites properties derived from FT-IR studies of Py, Pn and CO sorption.

\begin{tabular}{cccccccc}
\hline & $\mathbf{B} / \mathbf{L}_{\mathbf{P y}}{ }^{\mathbf{a}}$ & $\mathbf{B} / \mathbf{L}_{\mathbf{P n}}{ }^{\mathbf{b}}$ & $\mathbf{P y H}^{+}{ }_{\mathbf{4 5 0}} / \mathbf{P y H}^{+} \mathbf{1 7 0}^{\mathbf{a}}$ & $\mathbf{P y L}_{\mathbf{4 5 0}} / \mathbf{P y L}_{\mathbf{1 7 0}}{ }^{\mathbf{a}}$ & $\boldsymbol{\Delta v}_{\mathbf{C O}} \ldots \mathbf{O H}^{\mathbf{c}} \mathbf{c m}^{-\mathbf{1}}$ & $\mathbf{A F}_{\mathbf{B}} \mathbf{d}_{\mathbf{\%}}$ & $\mathbf{A F}_{\mathbf{L}} \mathbf{d}_{\mathbf{\%}}$ \\
\hline micro-ZSM-5 & 11.3 & 7.9 & 0.94 & 0.99 & 315 & 12 \\
deSi-ZSM-5 & 3.5 & 2.4 & 0.84 & 0.91 & 306 & 17 \\
deSi-ZSM-5\&Ac(m) & 4.9 & 3.5 & 0.84 & 0.98 & 303 & 28 \\
deSi-ZSM-5\&Ac(s) & 4.9 & 3.6 & 0.83 & 0.98 & 304 & 36 \\
\hline
\end{tabular}

${ }^{a}$ from Py adsorption: the ratio of Brønsted (B) and Lewis $(\mathrm{L})$ acid site concentrations $\left(\mathrm{B} / \mathrm{L}_{\mathrm{Py}}\right)$; the strength of Brønsted acid sites represented the $\mathrm{PyH}^{+}$and Lewis acid sites (PyL) preserved upon desorption at $450{ }^{\circ} \mathrm{C}, \mathrm{PyH}^{+}{ }_{450} / \mathrm{PyH}^{+}{ }_{170}$ and $\mathrm{PyL}_{450} / \mathrm{PyL}_{170}$, resp. ${ }^{\mathrm{b}}$ from Pn adsorption: the ratio of Brønsted (B) and Lewis (L) acid site concentrations $\left(\mathrm{B} / \mathrm{L}_{\mathrm{Pn}}\right)$ accessible to bulky Pn molecules. ${ }^{\mathrm{C}}$ from $\mathrm{CO}$ sorption: the shift of $\mathrm{Si}(\mathrm{OH}) \mathrm{Al}$ group engaged in hydrogen bonding with $\mathrm{CO}$ molecules represents the acid strength of sites. ${ }^{\mathrm{d}}$ Accessibility factors of Brønsted $\left(\mathrm{AF}_{\mathrm{B}}\right)$ and Lewis $\left(\mathrm{AF}_{\mathrm{L}}\right)$ acid sites, i.e., shared (expressed in \%) acid sites accessible to bulky Pn concerning their total concentration (Py) [19].

The impact of the dealumination on the acidic properties of the deSi-ZSM- 5 zeolite was examined comprehensively by probe molecule sorption in situ FT-IR spectroscopic studies. The detailed acidic feature assessment was performed with the use of pyridine (Py), pivalonitrile (Pn) and carbon monoxide (CO) to ascertain the total concentration, accessibility and nature of acid sites, respectively. The Py $\left(\mathrm{Py}_{450} / \mathrm{Py}_{170}\right)$ and $\mathrm{CO}\left(\Delta v_{\mathrm{CO}} \ldots \mathrm{OH}\right)$ sorption results also served to assess the acid sites' strength. Py as 
a probe molecule (kinetic diameter $0.54 \mathrm{~nm}$ ) can penetrate the 10-ring channels of ZSM-5 zeolites and provide information on the total concentration of acid sites [20]. Pn is a branched molecule (kinetic diameter $0.69 \mathrm{~nm}$ ) able to reach only the acid sites on the external surface of 10-ring zeolites and sites located near the pore entrances $[19,21]$; thus, it can be considered representative of LDPE molecules. The desilication led to an increase of the total concentration of acid sites (Supplementary Figures S4 and S5) due to the selective extraction of silicon species from the zeolite framework [4]. Upon subsequent dealumination, a predictable decrease in the number of Brønsted (B.a.s.) and Lewis (L.a.s.) acid sites was found.

As aforementioned, all the modified materials showed superior catalytic activity over the microporous counterpart. The following order of activity was found: micro-ZSM- $5<$ deSi-ZSM- 5 $<$ deSi-ZSM-5(s) < deSi-ZSM-5\&Ac(m). The reason for the superiority of deSi-ZSM-5\&Ac(m) was revealed through the scrutiny of the FT-IR spectroscopy results. Independently from the severity of dealumination, the ratios of $\mathrm{B} / \mathrm{L}$ (Brønsted/Lewis) acid sites reached by $\mathrm{Py}\left(\mathrm{B} / \mathrm{L}_{\mathrm{Py}}\right)$ or $\mathrm{Pn}\left(\mathrm{B} / \mathrm{L}_{\mathrm{Pn}}\right)$ were constant (Table 2). Therefore, no differentiation between mild and severe acid washes in removal of the $\mathrm{B}$ and $\mathrm{L}$ acid sites was found. Nevertheless, the Al-originating species giving rise to L.a.s. in the deSi-ZSM- 5 were predominantly removed over B.a.s. during the acid washing. The removal of this realuminated layer, detected as an excessive amount of L.a.s. in Py sorption, was the first feature directly related to the higher catalytic performance of both acid-washed deSi-ZSM-5\&Ac(s) and deSi-ZSM-5\&Ac(m). Upon dealumination, the acid strength was also preserved, in line with FT-IR results of Py and low-temperature CO sorption (Table 2). Furthermore, the alterations in the accessibility of $\mathrm{B}$ and $\mathrm{L}$ acid sites (expressed as $\mathrm{B} / \mathrm{L}_{\mathrm{Pn}}$ ratio) were simultaneous. What distinguished the mildly from the severely dealuminated sample was the explicitly expressed accessibility of $B$ and $L$ acid sites (Supplementary Figure S5). The accessibility factors [19] of Brønsted and Lewis acid sites ( $\mathrm{AF}_{\mathrm{B}}$ and $\mathrm{AF}_{\mathrm{L}}$, resp.) were used for quantification (Table 2). Only mild dealumination ensured the highest accessibility of the acid sites and, as a result, the highest catalytic performance. Thus, the accessibility of sites is a second feature governing the catalytic activity. Nevertheless, the enhancement of the $\mathrm{AF}_{\mathrm{B}}$ value for deSi-ZSM-5-Ac(m) was not accompanied by an increase of $S_{\text {meso }}$, as is usually observed $[4,19]$. This implies that the accessibility of the acid sites was hindered by the presence of realuminated layer in deSi-ZSM-5. Thus, a comprehensive description of the zeolites' hierarchisation degree when subsequent treatments are applied should consist of a dual factorisation by both the IHF and an acidic parameter, either $\mathrm{B} / \mathrm{L}_{\mathrm{Py}}$ or $\mathrm{AF}$, presenting the full picture of acidity. The $\mathrm{AF} \times \mathrm{IHF}$ or $\mathrm{B} / \mathrm{LPy} \times \mathrm{IHF}$ coupled factors are a proper measure of the changes accompanying a wide range of post-synthesis modifications and were later used to compare the zeolites' performance in LDPE cracking. Besides the low accessibility of Brønsted acid sites, both desilicated and severely dealuminated samples were characterised by a declined accessibility of L.a.s. $\left(\mathrm{AF}_{\mathrm{L}}\right.$, Table 2). Thus, L.a.s. are supposed to be located in pore entrances or close to them, forming a realuminated layer, thus limiting the access for bulky Pn molecules. The overall accessibility of the acid sites should increase with Si/Al ratio [13]. However, the opposite finding for deSi-ZSM-5\&Ac(s) implied a redistribution of aluminium in the zeolite framework disturbing the accessibility of acid sites.

The preferential location of aluminium on the external surface was displayed by not only the declined accessibility of acid sites but mainly in the L.a.s speciation. Therefore, the nature of Lewis acid sites was identified as next, a third one, feature affecting the catalytic activity of the post-treated zeolites. Carbon monoxide is a probe molecule particularly suitable to discriminate the nature of L.a.s. Valuable information about the speciation and strength of Lewis acid sites can be attained from $\mathrm{CO}$ sorption, as the position of the $\mathrm{CO}$ band strongly depends on the electron-withdrawing properties of Lewis acid sites. Upon Py-thermodesorption studies, no distinct differences between the average strength of L.a.s. were found (Table 2). Therefore, to fully understand the alterations of the catalytic activity caused by the dealumination process, FT-IR studies of low-temperature CO sorption were undertaken (Figure 3). The spectra of the fully CO-saturated L.a.s. (2188, 2197, 2220 and $2226 \mathrm{~cm}^{-1}$ bands) demonstrated the dependence of their population on the applied post-treatment 
procedures. The IR spectra of $\mathrm{CO}$ adsorbed also displayed a band at $2174 \mathrm{~cm}^{-1}$ identified as CO hydrogen-bonded to Brønsted acid sites. The desilication (deSi-ZSM-5) led to a significant upsurge of strong L.a.s. from dehydroxylation (band at $2226 \mathrm{~cm}^{-1}$ ), which was accompanied by the appearance of weak Lewis acid sites (band at $2197 \mathrm{~cm}^{-1}$ ). In turn, a mild acid washing (deSi-ZSM-5\&Ac(m)) ensured the total leaching of the strong L.a.s., but only slight changes in the electron-accepting character of weak L.a.s. were found (band downshifted to $2188 \mathrm{~cm}^{-1}$ ). Harsher dealumination conditions (desi-ZSM-5\&Ac(s)) had an impact on L.a.s. characteristics, similarly to desilication treatment. The L.a.s. newly formed by the dehydroxylation were more heterogeneous, as manifested by two bands at 2226 and $2220 \mathrm{~cm}^{-1}$. Similarly, such heterogeneity is also observed for L.a.s. of weak electron-accepting properties (bands at 2197 and $2188 \mathrm{~cm}^{-1}$ ). After desilication, the appearance of strong Lewis acid sites from dehydroxylation seemed to be the main factor restricting the Brønsted acid sites' accessibility $\left(\mathrm{AF}_{\mathrm{B}}\right.$, Table 2$)$, and ultimately reducing the catalytic performance. The strong Lewis acid sites blocked micropore entrance, as was concluded from Pn sorption studies (Supplementary Figure $\mathrm{S} 5, \mathrm{AF}_{\mathrm{L}}$ in Table 2) and, as a result, the accessibility of B.a.s. was significantly restricted. When properly adjusted dealumination conditions are applied, the hierarchical porosity becomes more open. The entrances to micropores from the mesopore surfaces were not clogged by Lewis residues longer, and were thus free of additional constraints. Harsher dealumination conditions suppressed the accessibility of acid sites; again, L.a.s. from dehydroxylation were found.

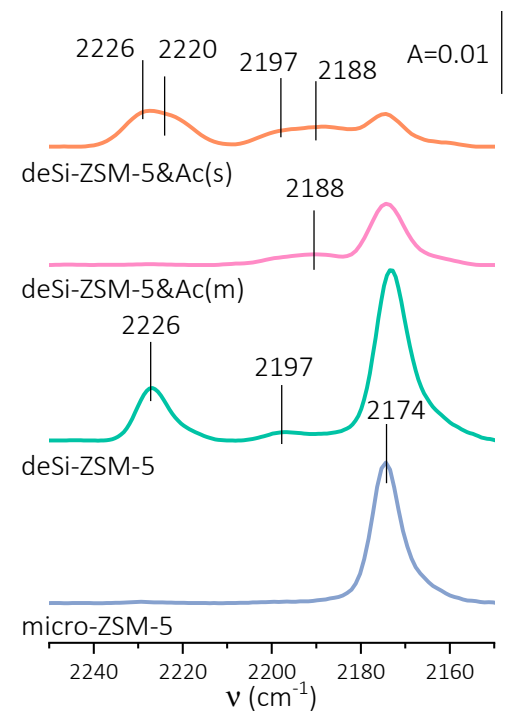

Figure 3. FT-IR spectra of $\mathrm{CO}$ sorbed at $-100{ }^{\circ} \mathrm{C}$ onto zeolites after full saturation of Lewis acid sites, (for clarity, only spectra without full saturation of Brønsted acid sites are presented).

However, the electron-acceptor properties of the L.a.s. in the dealuminated materials differed from those formed after desilication: the less electron-acceptor sites (of lower strength) were more populated in both acid-leached materials and, most importantly, the overall L.a.s. concentration was significantly lowered (Table 2, Supplementary Figure S5). Consequently, the impact of L.a.s. on the catalytic performance was less negative and deSi-ZSM-5\&Ac(s) was still more active than deSi-ZSM-5 in the low-temperature range. It seems that the high concentration and strength of Lewis acid sites in deSi-ZSM- 5 zeolite are responsible for restricted accessibility to Brønsted acid sites, what negatively affected the catalytic performance. The $\mathrm{CO}$ adsorption results gave a significant insight into the speciation of Lewis acid sites, nevertheless to fully understand the nature of the realuminated layer, the Py sorption data were needed. The Py sorption proved that Al-species giving rise to L.a.s. in deSi-ZSM-5 finally formed the realuminated layer. Its removal led to an increase of $\mathrm{B} / \mathrm{L}_{\mathrm{Py}}$ ratios and enhanced catalytic activity for both acid-washed samples. To highlight the influence of the realuminated layer on LDPE-cracking activity, the $\mathrm{B} / \mathrm{L}_{\mathrm{Py}}$ ratio, altered upon its formation (desilication) and subsequent 
removal (acid-washing), was coupled with IHF. Then $\mathrm{B} / \mathrm{L}_{\mathrm{Py}} \times$ IHF coupled factors were plotted against the $T_{20}$ and $T_{80}$ values (Figure 4 , left). The linear dependence confirmed that both the outer Lewis sites' etching and hierarchical porosity played a significant role in the LDPE catalytic cracking. To further unwrap the impact of the three identified features on the catalytic activity, the $\mathrm{AF}_{\mathrm{B}} \times \mathrm{IHF}$ coupled factors were also plotted against the $T_{20}$ and $T_{80}$ values (Figure 4). The deSi-ZSM-5\&Ac(s) and deSi-ZSM- 5 samples displayed almost identical $\mathrm{AF}_{\mathrm{B}} \times \mathrm{IHF}$ values; nevertheless, at lower conversion, the former outperformed the latter. At this stage, at low temperatures, the polymer might be cracked only at the weak acid sites. The most stable carbocations were cracked at the highest temperatures, or, in other words, in the presence of the strongest sites. The two-step nature of the cracking process over zeolites was also well represented in the decomposition LDPE rates (Figure 1). At higher conversion $\left(T_{80}\right.$, Figure 4$)$, when the preliminary cracking was realized over the external surface, the accessibility of B.a.s. played a major role and the impact of the realuminated layer negligible. Thus, the conversion curves for deSi-ZSM-5 and deSi-ZSM-5\&Ac(s) showed a similar course (Figure 1). This points to the importance of realuminated-layer removal after desilication. For deSi-ZSM-5, both the high L.a.s. share in the overall acidity and low B.a.s accessibility negatively affected the catalytic performance at lower conversion values $\left(T_{20}\right)$. The L.a.s. in excessive amount were proved to quench the LDPE cracking over desilicated ITQ-4 at low conversion (10\%), to a degree found for its microporous counterpart [22]. The deSi-ZSM-5\&Ac(s) being free of realuminated layer was able to keep up with deSi-ZSM-5\&Ac(m) activity only in the low conversion range; later on, the limited accessibility forced a drop of activity to the levels observed for deSi-ZSM-5. On the other hand, the deSi-ZSM-5\&Ac $(m)$ outperformed other zeolites as it combined the best feature, i.e., the highest $\mathrm{AF}_{\mathrm{B}}$ which was not suppressed by L.a.s. originating from either dehydroxylation or realuminated layer.
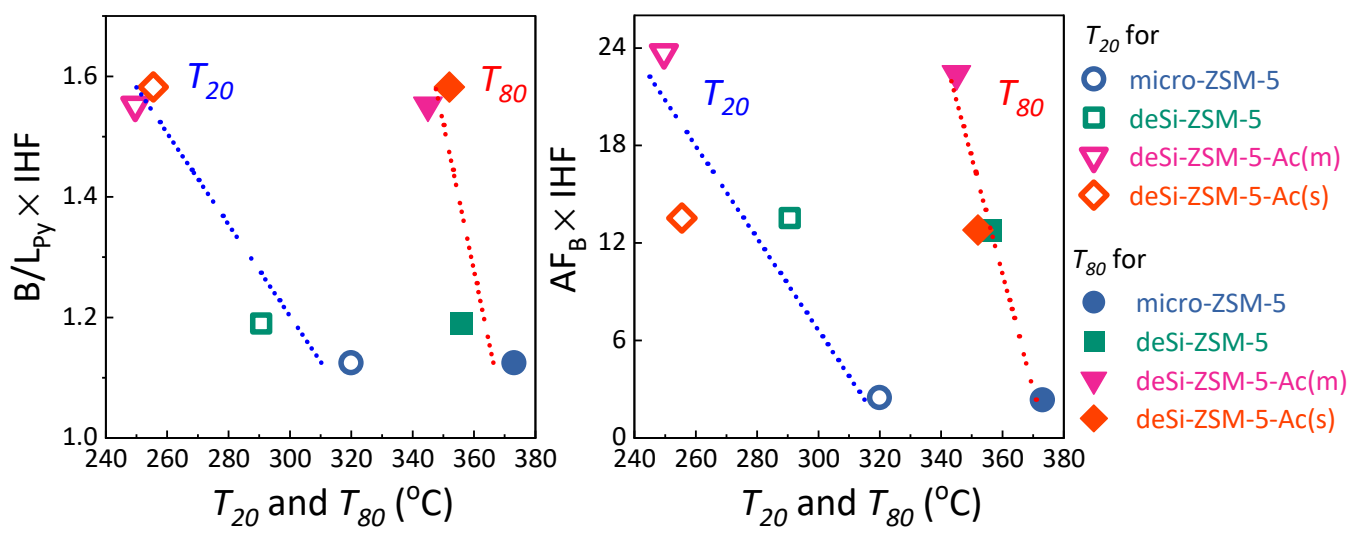

Figure 4. (left) $\mathrm{B} / \mathrm{L}_{\mathrm{Py}} \times \mathrm{IHF}$ and (right) $\mathrm{AF}_{\mathrm{B}} \times \mathrm{IHF}$ coupled factors (B/L $\mathrm{L}_{\mathrm{Py}}$-ratio of B.a.s. to L.a.s; $\mathrm{IHF}$-indexed hierarchy factor; $\mathrm{AF}_{\mathrm{B}}$-accessibility factor of B.a.s.) plotted against the temperatures for $20 \%$ and $80 \%$ conversion $\left(T_{20}\right.$ and $\left.T_{80}\right)$ for LDPE cracking.

The LDPE cracking over the studied catalysts was followed by FT-IR operando studies with on-line coupled GC analysis of the resulting products. The reaction temperature was adjusted to avoid the input from thermal cracking, i.e., $230{ }^{\circ} \mathrm{C}$ was applied. Two sets of information were provided by the FT-IR-GC operando studies (Figure 5). The quantitative analysis of the overall reaction products showed that deSi-ZSM- 5 and deSi-ZSM- $5 \& A c(m)$ increased the selectivity to value-added light $C_{3}-C_{5}$ hydrocarbons at the expense of heavier $C_{7+}$ fraction. This effect was more pronounced for the deSi-ZSM- 5 catalyst, where a higher concentration of B.a.s. ensured a higher share of light hydrocarbon production. The deSi-ZSM-5\&Ac $(\mathrm{m})$ catalyst delivered a $\mathrm{C}_{7+}$ fraction in lower amounts than the micro-ZSM- 5 catalysts (19\% to $22 \%$ ); nevertheless, the share of $C_{3}-C_{5}$ was comparable. This implied that the concentration of Brønsted acid sites dominated the selectivity of the LDPE-cracking reaction, while both acidity and hierarchical porosity governed the overall activity by means of $T_{20}$ and $T_{80}$ (Figure 1). An additional insight was provided by scrutiny of the bands representative for $\mathrm{CH}_{3}$ 
$\left(2960 \mathrm{~cm}^{-1}\right)$ and $\mathrm{CH}_{2}\left(2925 \mathrm{~cm}^{-1}\right)$ groups. The ratio of $\mathrm{CH}_{3} / \mathrm{CH}_{2}$ band intensities was used to evaluate the susceptibility of PE end-chain cracking over catalysts (Figure 5). For micro-ZSM-5, the ratio increased in the first $3 \mathrm{~min}$, reaching 0.75 as maximum, and then a successive drop was seen. Two-step curves are displayed for the hierarchical catalysts, which implied, similarly to the conversion curves (Figure 1), a dual nature of the cracking process. The end-chain cracking dominated for microporous zeolite because LDPE chains must get inside the channels, where they are cracked on strong acid sites. For desilicated zeolites, after some time middle-chain cracking began to dominate, which may suggest that the development of mesoporosity allowed easier diffusion and thus middle-chain cracking. Further increase in accessibility resulted in more noticeable middle-chain cracking. A slightly higher value of the $\mathrm{CH}_{3} / \mathrm{CH}_{2}$ ratio throughout the whole reaction time for the deSi-ZSM-5 than for deSi-ZSM-5\&Ac(m) catalyst was reflected in the increased share of $C_{3}-C_{5}$ hydrocarbons in the product distribution. After preliminary cracking, during the first 5 min of reaction, the observed trends corresponded well with the $\mathrm{AF}_{\mathrm{B}} \times \mathrm{IHF}$ coupled factors. However, at longer time-spans in isothermal conditions, the concentration of B.a.s. seemed to play crucial role in cracking of LDPE, as the deSi-ZSM-5\&Ac(m) catalysts resembled the micro-ZSM-5.
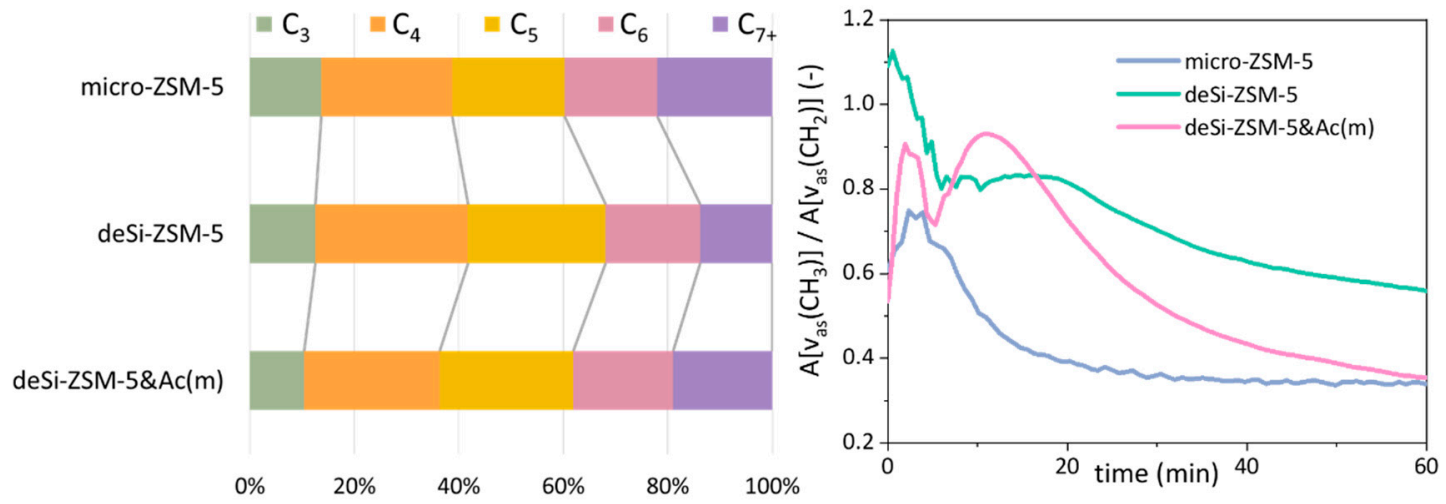

Figure 5. (left) Selectivity to $\mathrm{C}_{\mathrm{n}}$ groups of hydrocarbons in total amount of products formed upon cracking of LDPE; (right) $\mathrm{CH}_{3} / \mathrm{CH}_{2}$ band intensity ratio derived from FT-IR operando studies as a function of time during LDPE cracking for microporous (micro), desilicated (deSi) and mildly acid-washed $(\mathrm{Ac}(\mathrm{m}))$ ZSM-5 zeolites.

\section{Conclusions}

A careful dealumination procedure leads to the effective redistribution of $\mathrm{Al}$ species onto the mesopore surface. Such a procedure, therefore, offers the highest possible accessibility of the acid sites. The micropore entrances become free of the restrictions from blocking by strong Lewis residues. To the best of our knowledge, such a correlation between the selection of dealumination conditions and the restricted accessibility of the Brønsted acid influencing polymer-cracking activity is reported here for the first time. Three co-dependent features ruling the cracking activity of hierarchical ZSM-5 zeolites were identified. Their impacts were rationalised both in low and high conversion ranges of LDPE cracking. These correlations, and the importance of the acid sites' accessibility, were directly reflected in the catalytic performance and could serve as a prerequisite for catalysts' applicability. The FT-IR-GC operando studies proved that the selectivity of LDPE cracking in isothermal conditions is ruled by catalyst's acidic feature. The surface of deSi-ZSM-5\&Ac(m) catalysts free of Al-realuminated ensured the highest catalytic performance. The temperature needed to achieve the highest conversion was significantly reduced while the selectivity for value-added $C_{3}-C_{5}$ hydrocarbons was maintained. 


\section{Materials and Methods}

\subsection{Materials}

The micro-ZSM-5 zeolite ( $\mathrm{NH}_{4}$-form, Zeolyst, Kansas, MO, USA, CBV 5524G) was transformed to the $\mathrm{H}$-form by calcination at $550{ }^{\circ} \mathrm{C}$ for $5 \mathrm{~h}$ with a rate of $2{ }^{\circ} \mathrm{C} / \mathrm{min}$. The desilication procedure was carried out with the use of a $0.2 \mathrm{M}$ solution of $\mathrm{NaOH}$ at a temperature of $80^{\circ} \mathrm{C}$ for $0.5 \mathrm{~h}$. After desilication, the mixture was put into an ice bath, filtered and washed thoroughly with distilled water until neutral $\mathrm{pH}$ was reached. Next, a fourfold ion-exchange with the use of a $0.5 \mathrm{M} \mathrm{NH}_{4} \mathrm{NO}_{3}$ solution was performed $\left(60^{\circ} \mathrm{C}, 1 \mathrm{~h}\right)$. The obtained sample was filtrated, washed and dried at room temperature. The dealumination treatments were then applied at a temperature of $80^{\circ} \mathrm{C}$ for $1 \mathrm{~h}$. Mild acid washes were perfumed with the use of a $0.05 \mathrm{M}$ solution of $\mathrm{HNO}_{3}$, while the severe acid washing was done with $0.10 \mathrm{M}$ of the same acid. After the acid treatment, the samples were filtrated, washed and dried at room temperature. All modified samples were calcined at $550{ }^{\circ} \mathrm{C}$ for $5 \mathrm{~h}$, at a rate of $2{ }^{\circ} \mathrm{C} / \mathrm{min}$.

\subsection{Characterisation of the Catalysts}

The chemical composition was assessed by inductively coupled plasma-optical emission spectroscopy (ICP-OES, PerkinElmer, Krakow, Poland, Optima 2100DV). The measurements were performed to determine $\mathrm{Si} / \mathrm{Al}$ molar ratios of the parent and modified samples. The sample, typically 80-100 mg, was digested in a Teflon vessel with the use of $\mathrm{HCl}\left(4 \mathrm{~cm}^{3}, 35 \%\right)$ and $\mathrm{HF}\left(0.4 \mathrm{~cm}^{3}, 48 \%\right)$. The final concentration was adjusted with deionised water.

Wide-angle powder X-ray diffraction (XRD) patterns were obtained using a Rigaku Multiflex diffractometer equipped with $\mathrm{Cu} \mathrm{K} \alpha$ radiation $(40 \mathrm{kV}, 40 \mathrm{~mA})$. The relative crystallinity was assessed by comparing the integrated area of the characteristic reflections of the MFI type structure in the range of $22.5^{\circ}$ to $25.0^{\circ}$. The crystallinity of the calcined micro-ZSM-5 sample was referenced as $100 \%$.

The porosity of the materials was studied by low-temperature adsorption/desorption of nitrogen. The isotherms were obtained from a Quantachrome Autosorb-1-MP gas sorption analyser. Before each measurement, the samples were heated at $350{ }^{\circ} \mathrm{C}$ and evacuated under high-vacuum conditions (ca. $10^{-5} \mathrm{mbar}$ ) for $16 \mathrm{~h}$. The micropore volume $\left(V_{\text {micro }}\right)$ and surface area of micropores $\left(S_{\text {micro }}\right)$ were calculated using the $t$-plot method. The specific surface area $\left(S_{B E T}\right)$ was calculated based on the Brunauer-Emmet-Teller (BET) method, following the recommendations of Rouquerol et al. $[18,23]$. The pore size distributions were obtained from the adsorption isotherm branch using the Barrett-Joyner-Halenda (BJH) model [24].

The electron micrographs were obtained in a JEOL 2100F transmission electron microscope working at $200 \mathrm{kV}$, equipped with a field emission gun (FEG). EDX and STEM detectors were used, working under bright and dark modes.

The FT-IR studies with the use of probe molecules were performed on Vertex 70 spectrometer (Bruker, Poznan Poland) equipped with an MCT detector. The applied resolution was set at $2 \mathrm{~cm}^{-1}$. The spectra for quantitative analysis were normalised to the same sample mass (10 mg). The study was performed with the use of pyridine (Py, $\geq 99.8 \%$, Sigma-Aldrich, Grajewo, Poland), pivalonitrile (Pn, 98\%, Sigma-Aldrich, Grajewo, Poland) and carbon monoxide (CO, Linde Gas Poland, 99.95\%) as probe molecules. Before the analysis, the samples were pressed into self-supporting discs $\left(5-10 \mathrm{mg} \cdot \mathrm{cm}^{-2}\right)$ and pre-treated in situ at $500^{\circ} \mathrm{C}$ under high-vacuum $\left(10^{-6} \mathrm{mbar}\right)$ conditions for $1 \mathrm{~h}$.

Py sorption: Py vapours ( $>20 \mathrm{Tr}$ ) in an amount sufficient to neutralise all acid sites were introduced into the FT-IR cell at $170{ }^{\circ} \mathrm{C}$. Next, to remove the gaseous and physisorbed Py, evacuation at the same temperature was performed. This was confirmed by the disappearing of the respective Py bands. The concentration of acid sites was estimated based on the respective bands' intensities (band height) and their absorption coefficients $\left(1545 \mathrm{~cm}^{-1}, \mathrm{PyH}^{+}, 0.07 \mathrm{~cm}^{2} \cdot \mu \mathrm{mol}^{-1}\right.$ and the $1450 \mathrm{~cm}^{-1}$, PyL, $\left.0.10 \mathrm{~cm}^{2} \cdot \mu \mathrm{mol}^{-1}\right)[20,25]$. The acid strength was determined in thermodesorption experiments. The preservation of the $1545 \mathrm{~cm}^{-1}$ band $\left(\mathrm{PyH}^{+}\right)$and $1455 \mathrm{~cm}^{-1}(\mathrm{PyL})$ upon desorption at $450{ }^{\circ} \mathrm{C}$ was 
estimated. The ratios of $\mathrm{PyH}^{+}{ }_{450} / \mathrm{PyH}^{+}{ }_{170}$ and $\mathrm{PyL}_{450} / \mathrm{PyL}_{170}$ were then taken as measures of the acid strength of Brønsted and Lewis sites, respectively.

Pn sorption: Pn sorption in an excess amount was done at room temperature. The gaseous and physisorbed molecules were then removed over $20 \mathrm{~min}$ evacuation at the same temperature. The concentration of the sites accessible to the Pn molecules was estimated based on respective bands intensities (band height) and their absorption coefficients $\left(2277 \mathrm{~cm}^{-1}, \mathrm{Pn} \ldots \mathrm{H}^{+}, 0.11 \mathrm{~cm}^{2} \cdot \mu \mathrm{mol}^{-1}\right.$ and $2305 \mathrm{~cm}^{-1}$, Pn ... L, $0.15 \mathrm{~cm}^{2} \cdot \mu \mathrm{mol}^{-1}$ ) [19].

CO sorption: The sorption of $\mathrm{CO}$ was performed at $-100{ }^{\circ} \mathrm{C}$. The Lewis acid sites' nature was studied in experiments involving sorption of small doses of carbon monoxide. The total saturation of Lewis sites was monitored as the maximum intensities of the bands in the region of $2300-2180 \mathrm{~cm}^{-1}$. The total saturation of Lewis sites was also documented by the appearance of the $\mathrm{Si}(\mathrm{OH}) \mathrm{Al} \cdots \mathrm{CO}$ band at $2174 \mathrm{~cm}^{-1}$, as Brønsted sites are able to ligate $\mathrm{CO}$ molecules in the next order due their lower electron-accepting properties compared to Lewis sites. The dosing of $\mathrm{CO}$ was then increased, and the total saturation of Brønsted acid sites was observed. The downshift $\left(\Delta v_{\mathrm{CO}} \ldots \mathrm{OH}\right)$ of the $\mathrm{Si}(\mathrm{OH}) \mathrm{Al} \ldots \mathrm{CO}$ band of the adducts was taken as a measure of the acid strength.

\subsection{Catalytic Cracking of Low-Density Polyethylene}

Low-density polyethylene (LDPE, $\leq 400$ microns) from Alfa Aesar (Haverhill, MA, USA, Product No.: 42607, Lot No.: P28D047) was used for the catalytic tests. Thermogravimetric analysis was performed using a TGA/SDTA Mettler Toledo apparatus. The polymer $(30 \mathrm{mg})$ and the zeolite powder $(10 \mathrm{mg})$ were thoroughly mixed in an agate mortar for $10 \mathrm{~min}$. A certain portion of the prepared fresh mixture (ca. $10 \mathrm{mg}$ ) was then transferred into an $\alpha-\mathrm{Al}_{2} \mathrm{O}_{3}$ crucible. During the analysis, a flow of nitrogen was supplied $(80 \mathrm{~mL} / \mathrm{min})$, and the temperature was raised from $30^{\circ} \mathrm{C}$ to $600{ }^{\circ} \mathrm{C}$ at a heating rate of $5{ }^{\circ} \mathrm{C} / \mathrm{min}$. The catalyst weight and the adsorbed water content were taken into account when calculating the conversion. The conversion was defined as the weight loss of the mixed LDPE and zeolite sample, taking into account the content of water in the zeolite sample. The coke amount was measured by separate TG measurement where the weight loss of the spent catalyst upon heating to $80{ }^{\circ} \mathrm{C}$ was checked. The amount of non-volatile products (not exceeding $3.7 \%$ for each sample) was included in percentage of conversion.

\subsection{Operando FT-IR-GC Studies of LDPE Cracking}

The LDPE cracking was studied in an operando system (Supplementary Figure S6) connected to a flow set-up with nitrogen as a carrier gas $(30 \mathrm{~mL} / \mathrm{min})$. The zeolites were mixed with LDPE (1:1), and pressed into self-supporting wafers (ca. $5.5-6 \mathrm{mg} / \mathrm{cm}^{2}$ ). The wafer was placed in a bespoke $2 \mathrm{~cm}^{3}$-volume IR quartz gas cell. The reaction cell allowed for the analysis of the gas phase and surface of catalysts simultaneously during the reaction. The reagents were transferred by $1 / 16$ " Teflon lines, heat-traced at $110^{\circ} \mathrm{C}$. Time-resolved FT-IR spectra were taken on a Vertex 70 Bruker FT-IR spectrometer (resolution $2 \mathrm{~cm}^{-1}$ ) over $60 \mathrm{~min}$ of reaction. The catalyst wafer in the cell was rapidly heated from room temperature up to $230{ }^{\circ} \mathrm{C}$ at $10{ }^{\circ} \mathrm{C} / \mathrm{s}$ ramping rate. The decomposition of LDPE was performed at $230^{\circ} \mathrm{C}$. The reaction products were analysed by gas chromatography (Agilent 7890B).

Supplementary Materials: The following are available online, Figure S1. XRD patterns for all studied samples. Figure S2. $\mathrm{N}_{2}$ adsorption/desorption isotherms and pore size distributions for all studied samples. Figure S3. TEM micrographs (left), Si and Al EDX maps (middle) and Si, Al and HAADF micrographs (right) of studied samples. Figure S4. FT-IR spectra of pyridine interacting with the studied catalysts at $170{ }^{\circ} \mathrm{C}$. Figure S5. Total concentration (full-colour) and share of accessible (pattern) Brønsted (B.a.s.) and Lewis (L.a.s.) acid sites from FT-IR studies of Py and Pn sorption versus Al content (grey line) from chemical analysis for all studied zeolites. Table S1 Acid sites properties derived from FT-IR studies of Py sorption. Figure S6. Real impression of the Operando reactor, showing the main sections. The rig allows feeding either gases or vapors, or both, using independent thermo-stated vapor-phase saturators. The mechanical parts are Teflon ${ }^{\mathrm{TM}}$ based that guarantee working under inert conditions and avoiding cross-contamination. The Reactor cell is a Transmission cell with a rapid heating. This allows to obtain quantitative data for kinetic or deactivation studies. Finally, the gas outlet can be analysed by a gas chromatograph, FT-IR gas cell or mass spectrometers that are connected on-line. 
Author Contributions: K.A.T. was the originator of the concept, and planned and supervised the experiments. K.P. undertook the modification and characterisation of materials with the FTIR of probe molecules and operando studies. K.G.-M. assisted in the interpretation of the spectroscopic and catalytic results. K.A.T. wrote the manuscript. All authors have read and agreed to the published version of the manuscript.

Funding: Financial support from the National Science Centre, Grant No. 2017/27/B/ST5/00191, is acknowledged.

Acknowledgments: We are grateful to Ignacio Melián-Cabrera for discussion.

Conflicts of Interest: The authors declare no conflict of interest. The funders had no role in the design of the study; in the collection, analyses, or interpretation of data; in the writing of the manuscript, or in the decision to publish the results.

\section{References}

1. Tarach, K.; Gora-Marek, K.; Tekla, J.; Brylewska, K.; Datka, J.; Mlekodaj, K.; Makowski, W.; Igualada Lopez, M.C.; Martinez Triguero, J.; Rey, F. Catalytic cracking performance of alkaline-treated zeolite Beta in the terms of acid sites properties and their accessibility. J. Catal. 2014, 312, 46-57. [CrossRef]

2. Zhou, Q.; Wang, Y.-Z.; Tang, C.; Zhang, Y.-H. Modifications of ZSM-5 zeolites and their applications in catalytic degradation of LDPE. Polym. Degrad. Stab. 2003, 80, 23-30. [CrossRef]

3. Serrano, D.P.; Aguado, J.; Escola, J.M.; Rodríguez, J.M. Influence of nanocrystalline HZSM-5 external surface on the catalytic cracking of polyolefins. J. Anal. Appl. Pyrol. 2005, 74, 353-360. [CrossRef]

4. Tarach, K.A.; Góra-Marek, K.; Martinez-Triguero, J.; Melián-Cabrera, I. Acidity and accessibility studies of desilicated ZSM-5 zeolites in terms of their effectiveness as catalysts in acid-catalysed cracking processes. Catal. Sci. Technol. 2017, 7, 858-873. [CrossRef]

5. Bonilla, A.; Baudouin, D.; Pérez-Ramírez, J. Desilication of ferrierite zeolite for porosity generation and improved effectiveness in polyethylene pyrolysis. J. Catal. 2009, 265, 170-180. [CrossRef]

6. Holm, M.S.; Taarning, E.; Egeblad, K.; Christensen, C.H. Catalysis with hierarchical zeolites. Catal. Today 2011, 168, 3-16. [CrossRef]

7. Caldeira, V.P.S.; Peral, A.; Linares, M.; Araujo, A.S.; Garcia-Muñoz, R.A.; Serrano, D.P. Properties of hierarchical Beta zeolites prepared from protozeolitic nanounits for the catalytic cracking of high density polyethylene. Appl. Catal. A-Gen. 2017, 531, 187-196. [CrossRef]

8. Blay, V.; Louis, B.; Miravalles, R.; Yokoi, T.; Peccatiello, K.A.; Clough, M.; Yilmaz, B. Engineering zeolites for catalytic cracking to light olefins. ACS Catal. 2017, 7, 6542. [CrossRef]

9. Tarach, K.A.; Martinez-Triguero, J.; Rey, F.; Gora-Marek, K. Hydrothermal stability and catalytic performance of desilicated highly siliceous zeolites ZSM-5. J. Catal. 2016, 339, 256-269. [CrossRef]

10. Verboekend, D.; Mitchell, S.; Milina, M.; Groen, J.C.; Pérez-Ramírez, J. Full Compositional Flexibility in the Preparation of Mesoporous MFI Zeolites by Desilication. J. Phys. Chem. C 2011, 115, 14193-14203. [CrossRef]

11. Groen, J.C.; Peffer, L.A.A.; Moulijn, J.A.; Pérez-Ramírez, J. Mechanism of Hierarchical Porosity Development in MFI Zeolites by Desilication: The Role of Aluminium as a Pore-Directing Agent. Chem. Eur. J. 2005, 11, 4983-4994. [CrossRef]

12. Verboekend, D.; Pérez-Ramírez, J. Design of hierarchical zeolite catalysts by desilication. Catal. Sci. Technol. 2011, 1, 879-890. [CrossRef]

13. Sadowska, K.; Gora-Marek, K.; Drozdek, M.; Kustrowski, P.; Datka, J.; Martinez Triguero, J.; Rey, F. Desilication of highly siliceous zeolite ZSM-5 with $\mathrm{NaOH}$ and $\mathrm{NaOH} /$ tetrabutylamine hydroxide. Microporous Mesoporous Mater. 2013, 168, 195-205. [CrossRef]

14. Verboekend, D.; Pérez-Ramírez, J. Desilication Mechanism Revisited: Highly Mesoporous All-Silica Zeolites Enabled Through Pore-Directing Agents. Chem. Eur. J. 2011, 17, 1137-1147. [CrossRef]

15. Pastvova, J.; Kaucky, D.; Moravkova, J.; Rathousky, J.; Sklenak, S.; Vorokhta, M.; Brabec, L.; Pilar, R.; Jakubec, I.; Tabor, E. Effect of Enhanced Accessibility of Acid Sites in Micromesoporous Mordenite Zeolites on Hydroisomerization of n-Hexane. ACS Catal. 2017, 7, 5781-5795. [CrossRef]

16. Dapsens, P.Y.; Mondelli, C.; Pérez-Ramírez, J. Highly Selective Lewis Acid Sites in Desilicated MFI Zeolites for Dihydroxyacetone Isomerization to Lactic Acid. ChemSusChem 2013, 6, 831-839. [CrossRef] [PubMed]

17. Chaouati, N.; Soualah, A.; Hussein, I.; Comparot, J.D.; Pinard, L. Formation of weak and strong Brønsted acid sites during alkaline treatment on MOR zeolite. Appl. Catal. A-Gen. 2016, 526, 95-104. [CrossRef] 
18. Thommes, M.; Kaneko, K.; Neimark Alexander, V.; Olivier James, P.; Rodriguez-Reinoso, F.; Rouquerol, J.; Sing Kenneth, S.W. Physisorption of gases, with special reference to the evaluation of surface area and pore size distribution (IUPAC Technical Report). Pure Appl. Chem. 2015, 87, 1051-1069. [CrossRef]

19. Sadowska, K.; Gora-Marek, K.; Datka, J. Accessibility of Acid Sites in Hierarchical Zeolites: Quantitative IR Studies of Pivalonitrile Adsorption. J. Phys. Chem. C 2013, 117, 9237-9244. [CrossRef]

20. Sadowska, K.; Gora-Marek, K.; Datka, J. Hierarchic zeolites studied by IR spectroscopy: Acid properties of zeolite ZSM-5 desilicated with $\mathrm{NaOH}$ and $\mathrm{NaOH}$ /tetrabutylamine hydroxide. Vib. Spectrosc. 2012, 63, 418-425. [CrossRef]

21. Bevilacqua, M.; Busca, G. A study of the localisation and accessibility of Brønsted and Lewis acid sites of H-mordenite through the FT-IR spectroscopy of adsorbed branched nitriles. Catal. Commun. 2002, 3, 497-502. [CrossRef]

22. Verboekend, D.; Groen, J.C.; Pérez-Ramírez, J. Interplay of Properties and Functions upon Introduction of Mesoporosity in ITQ-4 Zeolite. Adv. Funct. Mater. 2010, 20, 1441-1450. [CrossRef]

23. Rouquerol, J.; Llewellyn, P.; Rouquerol, F. Is the BET equation applicable to microporous adsorbents? In Studies in Surface Science and Catalysis; Llewellyn, P.L., Rodriquez-Reinoso, F., Rouqerol, J., Seaton, N., Eds.; Elsevier: Amsterdam, The Netherlands, 2007; pp. 49-56.

24. Barrett, E.P.; Joyner, L.G.; Halenda, P.P. The Determination of Pore Volume and Area Distributions in Porous Substances. I. Computations from Nitrogen Isotherms. J. Am. Chem. Soc. 1951, 73, 373-380. [CrossRef]

25. Góra-Marek, K.; Derewiński, M.; Sarv, P.; Datka, J. IR and NMR studies of mesoporous alumina and related aluminosilicates. Catal. Today 2005, 101, 131-138. [CrossRef]

Sample Availability: Samples of the compounds are not available from the authors.

(C) 2020 by the authors. Licensee MDPI, Basel, Switzerland. This article is an open access article distributed under the terms and conditions of the Creative Commons Attribution (CC BY) license (http://creativecommons.org/licenses/by/4.0/). 